\title{
Solution viscosity - molar mass relationships for poly(butylene succinate) and discussion on molar mass analysis
}

\author{
Q. Charlier ${ }^{1,2}$, E. Girard $^{1,2}$, F. Freyermouth $^{1,2}$, M. $_{\text {. }}$ Vandesteene $^{1,2}$, N. Jacquel $^{3}$, C. Ladavière $^{1,4}$, \\ A. Rousseau ${ }^{1,2}$, F. Fenouillot ${ }^{1,2 *}$ \\ ${ }^{1}$ Université de Lyon, F-69003 Lyon, France \\ ${ }^{2}$ INSA-Lyon, Ingénierie des Matériaux Polymères, IMP, CNRS UMR5223, F-69621 Villeurbanne, France \\ ${ }^{3}$ Roquette Frères, Division Recherche, F-62080 Lestrem, France \\ 4Université de Lyon, CNRS UMR5223, IMP@Lyon 1, 15 Boulevard Latarjet, F-69622 Villeurbanne, France
}

Received 23 September 2014; accepted in revised form 27 November 2014

\begin{abstract}
Poly(butylene succinate) (PBS) is currently developing due to its biodegradability and the similarity of its mechanical properties to those of polyolefins. Relationships between the number average molar mass, $\overline{M_{\mathrm{n}}}$, and solution viscosity such as $[\eta]$ and $\eta_{\text {red }}$ were derived for this aliphatic polyester. $\bar{M}_{\mathrm{n}}$ values were determined by end-group analysis and size exclusion chromatography (SEC). Mark-Houwink-Sakurada (MHS) parameters were proposed in two solvents and for the different molar masses and viscosity measurement methods. As an example, the MHS equations were respectively, $[\eta]=$ $6.4 \cdot 10^{-4} \cdot M_{\mathrm{n}}{ }^{0.67}$ in chloroform and $[\eta]=7.1 \cdot 10^{-4} \cdot \bar{M}_{\mathrm{n}}^{0.69}$ in 50/50 wt \% 1,2-dichlorobenzene/phenol at $25^{\circ} \mathrm{C}$ for molar masses measured by SEC in hexafluoro isopropanol (HFIP) with poly(methyl methacrylate) (PMMA) standards. Empirical relationships were also suggested to derive $\overline{M_{\mathrm{n}}}$ directly from reduced viscosity, $\eta_{\text {red, }}$, which is much easier to determine than intrinsic viscosity. With these data, the number average molar mass of PBS can be conveniently estimated from a single viscosity measurement. In addition, it was shown that PBS contains $1-2 \mathrm{wt} \%$ of cyclic oligomers produced during esterification and that molar masses determined by taking this fraction into account or not were significantly different, especially for long chains.
\end{abstract}

Keywords: biopolymers, poly(butylene succinate), molar mass, cyclic oligomers

\section{Introduction}

Poly(butylene succinate) (PBS) is one of the 'old' polyesters which regains interest because of the current preoccupation with the environment [1-3]. It is biodegradable and can be bio-based. Its thermal and mechanical properties are close to those of polyolefins and its processability is excellent while its durability is much lower due to possible hydrolysis. Indeed it recently drew attention from academia and industry [4-9] and now, the producers are trying to find applications in agriculture, fishery, forestry, civil engineering and other fields in which recycling of materials is challenging.

Poly(butylene succinate) is not a new polymer however it was not developed commercially in the 1950s or 1960s as was done with commodity polymers. As a consequence research has not been very active until now and basic data on PBS may be missing. Here we will focus on the topic of molar mass determination of PBS.

There are several ways to determine the number and weight average molar masses $\left(\overline{M_{\mathrm{n}}}, \overline{M_{\mathrm{w}}}\right)$ of a

\footnotetext{
${ }^{*}$ Corresponding author, e-mail: Francoise.Fenouillot@insa-lyon.fr (C) BME-PT
} 
polymer such as end-group analysis by titration or by ${ }^{1} \mathrm{H}-\mathrm{NMR}$ spectroscopy $\left(\overline{M_{\mathrm{n}}}\right)$, size exclusion chromatography (SEC) $\left(\overline{M_{\mathrm{n}}}, \overline{M_{\mathrm{w}}}\right.$ and $\left.\overline{M_{\mathrm{z}}}\right),\left(\overline{M_{\mathrm{n}}}\right)$, membrane osmometry $\left(\overline{M_{\mathrm{n}}}\right)$, light-scattering $\left(M_{\mathrm{w}}\right)$, and viscometric method $\left(\overline{M_{\mathrm{v}}}\right)[10,11]$.

Viscometry is a quick and simple method if dispersity data are not needed. It involves measuring the viscosity of dilute solutions of the polymer, from which the molar mass may be calculated since the relationship between the intrinsic viscosity, [ๆ], and the viscosity-average molar mass, $\overline{M_{v}}$, can be described by the well-known Mark-Houwink-Sakurada (MHS) equation (Equation (1)):

$\eta=k \cdot \overline{M_{\mathrm{v}}^{\mathrm{a}}}$

where $k$ and $a$ are constants for a given well-defined polymer-solvent-temperature system. In general, $\overline{M_{\mathrm{v}}}$ is not experimentally accessible, and in most reports, different average molecular masses $\left(\overline{M_{\mathrm{n}}}, \overline{M_{\mathrm{w}}}\right.$ and $\overline{M_{\mathrm{z}}}$ ), instead of the viscosity-average molar mass $\bar{M}_{\mathrm{v}}$, are substituted in the MHS equation, ignoring dispersity effects [12-14]. For poly(butylene succinate) $k$ and $a$ parameters are poorly defined in the literature [15-17].

On the other hand only size exclusion chromatography provides information on the molar mass distribution but it is not an easy technique for aromatic polyesters due to their poor solubility in commonly used SEC eluents. Aliphatic polyesters are more soluble but other difficulties arise. As an example, PBS is soluble in chloroform at room temperature but the refractive indexes of the polymer and the solvent are very close to each other $(\mathrm{d} n / \mathrm{d} c \sim$ $5 \cdot 10^{-2} \mathrm{~mL} \cdot \mathrm{g}^{-1}$ ) so inaccuracies are observed. The above comment illustrates one of the reasons why the determination of molar mass by SEC with a refractive index or light scattering detector for polyesters is controversial in chloroform. Several authors have recently highlighted that polystyrene-calibrated SEC measurements in chloroform overestimate the real $\overline{M_{\mathrm{n}}}$ by at least $50 \%$ in the range above $10^{4} \mathrm{~g} \cdot \mathrm{mol}^{-1}$ for poly( $\varepsilon$-caprolactone), polylactide and related copolyesters [18-24]. For these reasons, researchers have used complementary techniques such as MALDI-TOF mass spectrometry [19, 25]. Also, commercial polyesters often contain a fraction of cyclic oligomers, which may significantly affect the calculation of $\overline{M_{\mathrm{n}}}$. These inaccuracies are especially critical if the actual molar mass is needed with the aim of modelling polymerization or chemically modifying end-groups.

In this context, the objectives of this work were to provide information on the uncertainties attached to molar mass determination of PBS and develop a methodology to conveniently determine it. To this end, a series of linear PBS was synthesized, different methods for molar mass determination were explored, and the impact of the oligomer content on the data was estimated.

\section{Experimental}

\subsection{PBS synthesis}

A series of PBS samples with increasing molar mass were synthesized from succinic acid (SA) (99\% min, GADIV Petrochemical Ind., Haifa, Israel) and 1,4-butanediol (BDO) (99\%, Sigma-Aldrich, Saint-Quentin-Fallavier, France) via a two-step melt polycondensation reaction described in detail elsewhere [26]. Titanium (IV) n-butoxide (97\%, Sigma-Aldrich, Saint-Quentin-Fallavier, France) was used as the catalyst with $400 \mathrm{ppm}$ of Ti present in the final polymer.

Seven PBS samples were collected. The pellets were dried and stored in sealed aluminium bags. The first, PBS1, was collected after the esterification step. The others, denoted PBS2 to PBS7, were collected when the stirring torque variation reached $0.1,0.5,1,3,16$, and $22.5 \mathrm{Nm}$, respectively. They are numbered PBS1 to PBS7 in the order of increasing molar mass.

\subsection{Intrinsic viscosity and reduced viscosity determination}

An automated viscometer (AVS310, Schott Geräte, Hofheim, Germany), was used to determine the intrinsic viscosities of the PBS samples at $25 \pm 0.05^{\circ} \mathrm{C}$ in 50/50 wt\% 1,2-dichlorobenzene/phenol (solvent for the standard DIN53728) and in chloroform. The capillary diameter was $0.84 \mathrm{~mm}$ for the analysis in 50/50 wt \% 1,2-dichlorobenzene/phenol and $0.36 \mathrm{~mm}$ in chloroform in order to have sufficient accuracy for the flow time data. The PBS samples were solubilized at room temperature in both solvents. The solution viscosities were measured for four PBS concentrations varying from 2.5 to $10 \mathrm{~g} \cdot \mathrm{L}^{-1}$ in quadruplicate. The reduced viscosity, $\eta_{\text {red }}$, is the viscosity measured with a concentration equal to $5 \mathrm{~g} \cdot \mathrm{L}^{-1}$. 


\subsection{Molar mass determination by size exclusion chromatography (SEC)}

Polymer molar mass was assessed by size exclusion chromatography coupled to a UV detector (UV-272) and a refractive index (RI) detector (RI-1100) (Agilent, Germany, Waldbronn). $1 \mathrm{~g} \cdot \mathrm{L}^{-1}$ samples were eluted at a flow rate of $0.75 \mathrm{~mL} \cdot \mathrm{min}^{-1}$ with 1,1,1,3,3,3-hexafluoro-2-propanol (HFIP). The average molar masses $\overline{M_{\mathrm{n}}}$ and $\overline{M_{\mathrm{w}}}$ were determined with calibration method using poly(methyl methacrylate) (PMMA) standards. Calculation of the average molar masses was done using two methods, integrating low molar mass species between 100 and $1000 \mathrm{~g} \cdot \mathrm{mol}^{-1}$ or not.

\subsection{Molar mass determination by hydroxyl and carboxyl end-group contents}

Hydroxyl and carboxylic end-group concentrations, $N_{\mathrm{HC}}$ and $N_{\mathrm{CC}}$, were determined by ${ }^{1} \mathrm{H}$ NMR spectroscopy. A liquid state NMR spectrometer equipped with a $\mathrm{BBFO}+$ probe at $25^{\circ} \mathrm{C}$ was used (Avance III $400 \mathrm{MHz}$, Brucker, Wissembourg, France). Polymer samples were dissolved in deuterated chloroform containing tetramethylsilane (TMS) before analysis and trifluoroacetic anhydride (TFAA) was added to shift the $\underline{\mathrm{CH}}_{2} \mathrm{OH}$ and $\underline{\mathrm{CH}}_{2} \mathrm{COOH}$ signals of the hydoxyl and carboxylic end-groups (downfield shift of $\sim 0.6 \mathrm{ppm}$ ) [18]. The number of scans was 256 .

\subsection{Oligomer extraction and characterization}

To assess the quantity of the oligomers, $5 \mathrm{~g}$ of PBS samples were dispersed in $40 \mathrm{~g}$ of tetrahydrofurane (THF) over a period of three days under stirring. The dissolved oligomers were collected and the amount was quantified after evaporation at $25^{\circ} \mathrm{C}$ until a constant weight.

PBS oligomers were first analyzed by SEC (Shimadzu, DGU-20A3 + LC-20AD, Japan) with THF as the eluent. $5 \mathrm{~g} \cdot \mathrm{L}^{-1}$ samples were injected in three $5 \mu \mathrm{m}$ columns containing Waters Styragel HR2THF, HR1THF and HR0.5THF at $1 \mathrm{~mL} \cdot \mathrm{min}^{-1} \cdot \overline{M_{\mathrm{n}}}$ and $\overline{M_{\mathrm{w}}}$ were determined with a calibration method using polystyrene standards.

To compare the molar masses and to identify the nature (cyclic or linear) of the oligomers, the samples extracted with THF were analyzed by MALDITOF mass spectroscopy. All MALDI-TOF mass spectra were obtained with a Voyager-DE PRO (Applied Biosystems, Framingham, MA) equipped with a nitrogen laser emitting at $337 \mathrm{~nm}$ with a $3 \mathrm{~ns}$ pulse duration. The instrument was operated in reflector mode. The ions were accelerated under a potential of $20 \mathrm{kV}$. The positive ions were detected in all cases. The mass spectra were the sum of 300 shots and external mass calibration of the mass analyzer was used (a mixture of peptides, Sequazyme, Applied Biosystems, Framingham, MA). Samples were prepared by mixing $10 \mu \mathrm{L}$ of 2-(4'-hydroxyphenylazo) benzoic acid (HABA) at $0.1 \mathrm{M}$ in chloroform/THF $50 / 50 \mathrm{v} / \mathrm{v}$ with $10 \mu \mathrm{L}$ of sample (at $5 \mathrm{~g} \cdot \mathrm{L}^{-1}$ in THF). The resulting mixtures $(0.5 \mu \mathrm{L})$ were spotted on the MALDI sample plate and air-dried.

\section{Results and discussion}

\subsection{Intrinsic viscosity determination}

The intrinsic viscosity was determined for the seven PBS samples by two different methods:

1. At different concentrations, then extrapolation to infinite dilution.

2. Via the single-point method based on the solution's specific viscosity, $\eta_{\mathrm{sp}}$, and reduced viscosity, $\eta_{\text {red }}$, at only one specific concentration $(C=$ $\left.5 \mathrm{~g} \cdot \mathrm{L}^{-1}\right)$.

\subsubsection{Method using different concentrations}

The flow time of the pure solvent, $t_{0}$, and of four different PBS concentrations, $t$, was measured. Based on these time values, the specific viscosity $\eta_{\mathrm{sp}}$ and the relative viscosity $\eta_{\text {rel }}$ were calculated using Equations (2) and (3):

$$
\begin{aligned}
& \eta_{\text {rel }}=\frac{t}{t_{0}} \\
& \eta_{\mathrm{sp}}=\frac{t-t_{0}}{t_{0}}=\eta_{\text {rel }}-1
\end{aligned}
$$

The intrinsic viscosity can be determined when $\eta_{\mathrm{sp}}$ and $\eta_{\text {rel }}$ are known (Equation (4) and (5)):

$$
\begin{aligned}
& {[\eta]-k_{1}[\eta]^{2} C=\frac{\eta_{\mathrm{sp}}}{C}} \\
& {[\eta]-k_{2}[\eta]^{2} C=\frac{\ln \eta_{\mathrm{rel}}}{C}}
\end{aligned}
$$

where $k_{1}$ and $k_{2}$ are the Huggins and Kramer coefficients, respectively and $C$ is the concentration of the polymer solution in $\mathrm{g} \cdot \mathrm{L}^{-1}$.

For each PBS, $\eta_{\text {sp }} / C$ and $\left(\ln \eta_{\text {rel }}\right) / C$ were plotted against the concentration $C$ (Huggins and Kramer 


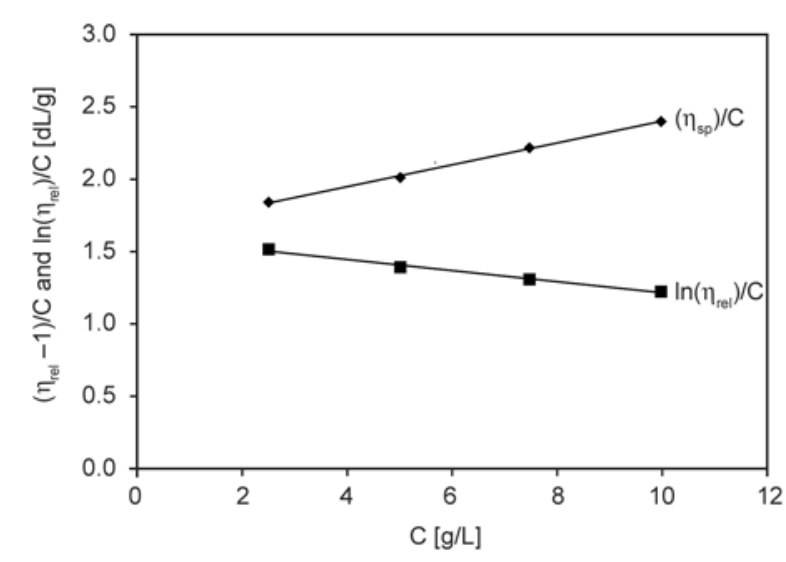

Figure 1. A typical Huggins-Kramer dual extrapolation plot for PBS7 $\left(M_{\mathrm{n}}=55,550 \mathrm{~g} \cdot \mathrm{mol}^{-1}\right.$ by SEC in HFIP versus PMMA standards) in 50/50 $\mathrm{wt} \% 1,2-$ dichlorobenzene/phenol at $25^{\circ} \mathrm{C}$. $(\diamond)\left(\eta_{\mathrm{sp}}\right) / C$, (घ) $\left(\ln \eta_{\text {rel }}\right) / C$.

plots) and the intrinsic viscosity was obtained by extrapolating the plots to infinite dilution [27]. An example of such a graph for PBS 7 is given in Figure 1.

The intrinsic viscosity data of PBS samples at $25^{\circ} \mathrm{C}$ in 50/50 wt $\%$ 1,2-dichlorobenzene/phenol and in chloroform are listed in Table 1.

\subsubsection{Method using a single-point}

The intrinsic viscosity, $[\eta]$, can be estimated with the measurement of specific viscosity, $\eta_{\mathrm{sp}}$, and relative viscosity, $\eta_{\text {rel }}$, for a single concentration with Equations (6), (7) and (8) [28-30]:
Solomon and Ciuta: $[\eta]=\frac{\sqrt{2\left(\eta_{\mathrm{sp}}-\ln \eta_{\text {rel }}\right)}}{C}$

Kuwahara: $[\eta]=\frac{\eta_{\mathrm{sp}}+3 \ln \eta_{\mathrm{rel}}}{4 C}$

Rao and Yaseen: $[\eta]=\frac{\left.\eta_{\mathrm{sp}}+\ln \eta_{\mathrm{rel}}\right)}{2 C}$

The previous method of Huggins and Kramer at different concentrations and the single-point method play two separate roles in characterizing the molar mass of polymers. The method of Huggins and Kramer is employed for procuring accurate information on the intrinsic viscosity, while the single-point method is fast for a reasonable estimation but is widely criticized in the literature. Both methods are consistent for some polymer-solvent couples but only if the solution has a low concentration $(\leq 0.2 \%)$ and low specific viscosity between 0.15 and 0.30 [27-32]. In most published studies where viscosity measurements were performed with PBS, these measurements were carried out in chloroform at 25 or $30^{\circ} \mathrm{C}[25,33-35]$. Some use the method developed by Huggins and Kramer [25, 33] while others prefer the single-point method. In this case, the most used equation is the one of Solomon and Ciuta [33, 34]. The concentration used for the single-point method was $2.5 \mathrm{~g} \cdot \mathrm{L}^{-1}$. Viscosity data extracted with the two methods are shown in Table 1.

Table 1. Comparison of $[\eta]$ of PBS determined from the Huggins and Kramer plots and from the single-point method determined in 50/50 $\mathrm{wt} \%$ 1,2-dichlorobenzene/phenol and chloroform at $25^{\circ} \mathrm{C}$

\begin{tabular}{|c|c|c|c|c|c|}
\hline \multirow{3}{*}{ Solvent } & \multirow{3}{*}{ PBS sample } & \multicolumn{4}{|c|}{$[\eta](\mathrm{dL} / \mathrm{g})\left( \pm 0.01 \mathrm{dL} \cdot \mathrm{g}^{-1}\right)$} \\
\hline & & \multirow{2}{*}{$\begin{array}{c}\text { Huggins-Kramer dual } \\
\text { extrapolation }\end{array}$} & \multicolumn{3}{|c|}{ Single point method ${ }^{\text {a) }}$} \\
\hline & & & Solomon and Ciuta & Kuwaraha & Rao and Yaseen \\
\hline \multirow{7}{*}{ 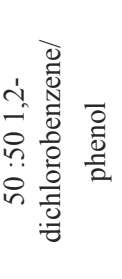 } & PBS1 & 0.11 & 0.11 & 0.11 & 0.11 \\
\hline & PBS2 & 0.33 & 0.33 & 0.33 & 0.34 \\
\hline & PBS3 & 0.67 & 0.67 & 0.66 & 0.68 \\
\hline & PBS4 & 0.81 & 0.83 & 0.82 & 0.84 \\
\hline & PBS5 & 1.30 & 1.29 & 1.28 & 1.33 \\
\hline & PBS6 & 1.50 & 1.48 & 1.46 & 1.53 \\
\hline & PBS7 & 1.62 & 1.62 & 1.60 & 1.68 \\
\hline \multirow{7}{*}{ 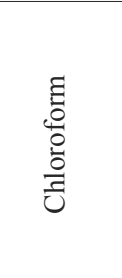 } & PBS1 & 0.08 & 0.08 & 0.08 & 0.08 \\
\hline & PBS2 & 0.25 & 0.25 & 0.24 & 0.25 \\
\hline & PBS3 & 0.50 & 0.50 & 0.49 & 0.50 \\
\hline & PBS4 & 0.57 & 0.57 & 0.57 & 0.58 \\
\hline & PBS5 & 0.89 & 0.89 & 0.89 & 0.91 \\
\hline & PBS6 & 0.99 & 0.99 & 0.99 & 1.01 \\
\hline & PBS7 & 1.07 & 1.08 & 1.07 & 1.10 \\
\hline
\end{tabular}

a) data determined for a concentration of $2.5 \mathrm{~g} \cdot \mathrm{L}^{-1}$. 
The data suggest that estimating $[\eta]$ of PBS using single-point calculation fits quite well with more than $97 \%$ accuracy recorded at relatively low concentrations and when the specific viscosity $\eta_{\mathrm{sp}}$ is not higher than 0.2 .

\subsection{Molar mass determination by end-groups analysis}

To calculate the equivalent Mark-Houwink-Sakurada parameters, the next step was to determine the molar mass of the PBS samples. Two methods were accessible: end-groups analysis and size exclusion chromatography. Both were done with and without an estimation of the cyclic oligomers fraction. End-groups analysis is presented first.

\subsubsection{End-groups analysis (without cyclic oligomers)}

The molar masses of PBS samples can be calculated if the chain end-groups content is known (Equation (9)):

$$
\bar{M}_{\mathrm{n}}=\frac{1}{\frac{N_{\mathrm{CC}}+N_{\mathrm{HC}}}{2}}
$$

where $N_{\mathrm{HC}}$ is the hydroxyl end group content, and $N_{\mathrm{CC}}$ is the carboxylic acid end group content, both measured by ${ }^{1} \mathrm{H}-\mathrm{NMR}$ and expressed in $\mathrm{mol} \cdot \mathrm{g}^{-1}$.
The carboxylic end-group concentration cannot be determined with a simple analysis in chloroform containing TMS because their signals superimpose to the $2.6 \mathrm{ppm}$ peak which corresponds to the succinic acid methylene groups inserted in the chains. The addition of trifluoroacetic anhydride (TFAA) which reacts quantitatively with both hydroxyl and carboxylic acid end-groups is necessary. As a consequence of that reaction, the peak corresponding to hydroxyl end-groups shifts downfield from 3.6 to $4.4 \mathrm{ppm}$ (H5), and two peaks corresponding to carboxylic end-groups appear at $2.7 \mathrm{ppm}(\mathrm{H} 2)$ and 2.9 ppm (H3) (Figure 2).

The $N_{\mathrm{HC}}$ and $N_{\mathrm{CC}}$ end-group concentrations were calculated using Equations (10) and (11):

$$
N_{\mathrm{HC}}=\frac{\frac{I_{\mathrm{H} 5}}{2}}{\sum I_{\mathrm{PBS}}} \cdot \frac{2}{M_{\mathrm{PBS}}}
$$

$N_{\mathrm{CC}}=\frac{\frac{I_{\mathrm{COOH} \text { at } 2.9 \mathrm{ppm}}}{2}}{\sum I_{\mathrm{PBS}}} \cdot \frac{2}{M_{\mathrm{PBS}}}$

where $M_{\mathrm{PBS}}$ is the molar mass of the repeat unit $\left(172 \mathrm{~g} \cdot \mathrm{mol}^{-1}\right) \cdot I_{\mathrm{H} 5}$ is the integral of trifluoroacetylated PBS hydroxyl end-groups at $4.4 \mathrm{ppm}$

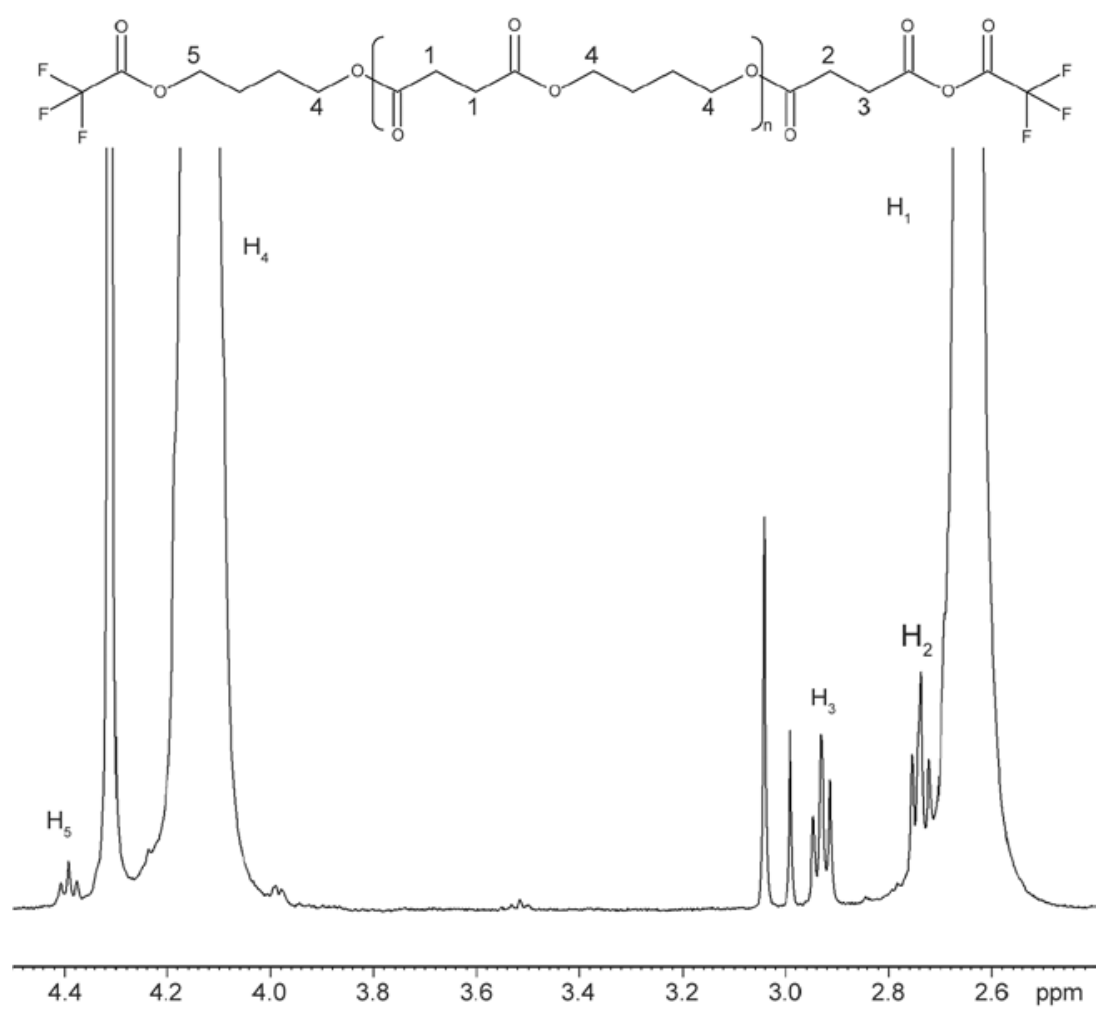

Figure 2. ${ }^{1} \mathrm{H}$ NMR spectrum of a sample of a trifluoroacetylated PBS (solvent: $\mathrm{CDCl}_{3}$ ) at $25^{\circ} \mathrm{C}$ 
$\left(-\mathrm{CH}_{2} \mathrm{OCOCF}_{3}\right)$ and $\Sigma I_{\mathrm{PBS}}$ is the sum of the integrals from all monomer units in the chains of PBS (Equation (12)):

$$
\sum I_{\mathrm{PBS}}=\frac{I_{\mathrm{H} 3}}{2}+\frac{I_{\mathrm{H} 5}}{2}+\frac{I_{\mathrm{H} 1}}{4}+\frac{I_{\mathrm{H} 4}}{4}
$$

where $I_{\mathrm{H} 1}$ is the integral at $2.6 \mathrm{ppm}$, referring to the methylene groups of succinic acid units in PBS and the peak at $4.2 \mathrm{ppm}$, referring to butanediol units in PBS.

$N_{\mathrm{HC}}, N_{\mathrm{CC}}$ data and the resulting molar masses of the PBS series are detailed in Table 2.

\subsubsection{End-groups analysis taking into account cyclic oligomers}

As reported in the literature, the synthesis of PBS may produce a non negligible amount of oligomers, especially cyclic species $[18,19]$. Most of the time, in scientific studies, PBS is purified to get rid of these species but commercial PBS clearly contains oligomers since dissolution/precipitation steps are not performed. In some cases it may be of importance to be able to account for their presence.

Equation (9) is not adapted for calculating the molar mass of a polymer that contains cycles. Indeed cyclic oligomers do not contain chain-ends, thus the molar mass derived with Equation (9) is overestimated since cycles monomer units are considered as being integrated into the linear chains population. It is possible to modify Equation (9) to account for cyclic oligomers only if their fraction and molar mass are known.

To this purpose, the mass fraction of cyclic oligomers, $w_{\text {cyclic }}$, of PBS samples was evaluated by extraction in THF and was found to be equal to 1-
$2 \mathrm{wt} \%$ (Table 2). The SEC analysis of the extractible fraction clearly shows four main elution peaks corresponding to species with estimated molar masses of $355,487,630$ and $801 \mathrm{~g} \cdot \mathrm{mol}^{-1}$ (Figure 3a). These four populations corresponding to cyclic oligomers could be discriminated more accurately by MALDITOF mass spectrometry: C2 $(367.1 \mathrm{~m} / \mathrm{z}), \mathrm{C} 3$ $(539.2 \mathrm{~m} / \mathrm{z}), \mathrm{C} 4(711.3 \mathrm{~m} / \mathrm{z})$, and C5 $(883.3 \mathrm{~m} / \mathrm{z})$ corresponding respectively to $\mathrm{Na}^{+}$cationized cyclic oligomers composed of 2, 3, 4 and 5 repeat units, i.e. $\mathrm{DPn}=4,6,8$ and 10 (Figure 3b). The average molar

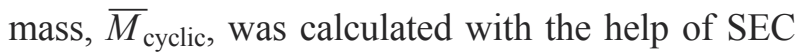
and MALDI-TOF mass spectrometry data (Table 2). The cyclic oligomer content, $N_{\mathrm{c}}$, may be expressed in $\mathrm{mol} \cdot \mathrm{g}^{-1}$ with Equation (13):

$N_{\mathrm{c}}=\frac{w_{\text {cyclic }}}{\bar{M}_{\text {cyclic }}}$

Then a corrected value of $\overline{M_{\mathrm{n}}}$ which includes cycles may be calculated with Equation (14):

$$
M_{\mathrm{n} \text { cor }}=\frac{1}{\frac{w_{\text {cyclic }}}{M_{\text {cyclic }}}+\frac{N_{\mathrm{CC}}+N_{\mathrm{HC}}}{2}}
$$

where $\overline{M_{\mathrm{n}}}$ values calculated with Equation (14) are listed in Table 2.

\subsection{Molar mass determination by size exclusion chromatography}

In addition to ${ }^{1} \mathrm{H}-\mathrm{NMR}, \overline{M_{\mathrm{n}}}$ was also measured by SEC with HFIP as the eluent and calibration with PMMA standards. It is necessary to note that polyester samples were not purified after synthesis. In order to get an idea of the influence of the small chains fraction, the molar mass was then calculated

Table 2. End-group concentrations and cycles fraction of PBS. $\overline{M_{\mathrm{n}}}$ data of PBS determined using two methods, SEC and

\begin{tabular}{|c|c|c|c|c|c|c|c|c|c|c|c|}
\hline \multirow[t]{2}{*}{ PBS } & \multirow{2}{*}{$\begin{array}{c}\mathbf{N}_{\mathrm{CC}} / \mathbf{N}_{\mathrm{HC}}{ }^{\mathrm{a})} \\
{\left[\mu_{\mathrm{eq}} \cdot \mathrm{g}^{-1}\right]}\end{array}$} & \multirow{2}{*}{$\begin{array}{l}\left.\mathbf{w}_{\text {cycles }}{ }^{b}\right) \\
{[\mathbf{w t} \%]}\end{array}$} & \multirow{2}{*}{$\begin{array}{c}\overline{\mathbf{M}}_{\mathbf{n}} \text { of cycles }{ }^{\mathrm{c})} \\
{\left[\mathrm{g} \cdot \mathrm{mol}^{-1}\right]}\end{array}$} & \multicolumn{2}{|c|}{$\begin{array}{c}{[\boldsymbol{\eta}]} \\
{\left[\mathrm{dL} \cdot \mathrm{g}^{-1}\right]}\end{array}$} & \multicolumn{2}{|c|}{$\begin{array}{c}\overline{\mathbf{M}}_{\mathbf{n}} \\
{\left[\mathbf{g} \cdot \mathbf{m o l}^{-1}\right]}\end{array}$} & \multirow{2}{*}{$\begin{array}{c}\text { Đ }^{\text {f) }} \\
\text { SEC }^{\text {e) }}\end{array}$} & \multicolumn{2}{|c|}{$\begin{array}{c}\overline{\mathbf{M}}_{\mathrm{n}} \text { with cyclic }{ }^{\mathrm{f}} \\
{\left[\mathrm{g} \cdot \mathrm{mol}^{-1}\right]}\end{array}$} & \multirow{2}{*}{$\begin{array}{l}\text { Number of } \\
\text { cycles per } \\
\text { PBS chain }\end{array}$} \\
\hline & & & & $\mathrm{CHCl}_{3}$ & $\mathbf{D} / \mathbf{P}^{\mathbf{d})}$ & $\mathrm{SEC}^{\mathrm{e})}$ & ${ }^{1} \mathrm{H}-\mathrm{NMR}$ & & $\mathrm{SEC}^{\mathrm{e})}$ & ${ }^{1} \mathrm{H}-\mathrm{NMR}$ & \\
\hline PBS1 & $812 / 1060$ & 1.9 & 484 & 0.08 & 0.11 & 1150 & 1070 & 2.6 & 1150 & 1030 & 0.046 \\
\hline PBS2 & $62 / 362$ & 2.1 & 473 & 0.25 & 0.33 & 10300 & 4710 & 1.7 & 5120 & 3890 & 0.52 \\
\hline PBS3 & $27 / 216$ & 0.9 & 442 & 0.50 & 0.67 & 25000 & 8260 & 1.8 & 8300 & 7080 & 0.51 \\
\hline PBS4 & $18 / 107$ & 1.1 & 432 & 0.57 & 0.81 & 29950 & 16000 & 1.8 & 9400 & 11500 & 0.77 \\
\hline PBS5 & $21 / 48$ & 1.4 & 450 & 0.89 & 1.30 & 48550 & 28900 & 1.9 & 11600 & 15000 & 1.53 \\
\hline PBS6 & $46 / 12$ & 1.6 & 466 & 0.99 & 1.50 & 55250 & 34100 & 2.0 & 12300 & 15600 & 1.93 \\
\hline PBS7 & $43 / 6$ & 2.0 & 459 & 1.07 & 1.62 & 55550 & 40400 & 2.0 & 11300 & 14400 & 2.46 \\
\hline
\end{tabular}
NMR (by taking cyclic oligomers into account or not)

${ }^{a)}$ Carboxylic and hydroxyl end-groups concentrations, ${ }^{\text {b) }}$ Cycles mass fraction, ${ }^{c}$ SEC versus PS standard and with THF as the eluent, ${ }^{\text {d) In }}$ $50 / 50 \mathrm{wt} \%$ dichlorobenzene/phenol, ${ }^{\text {e) }}$ SEC versus PMMA standards and with HFIP as the eluent, ${ }^{\mathrm{f}}$ Dispersity, ${ }^{\mathrm{g})}$ Average molar mass including the contribution of cyclic oligomers, ${ }^{\text {h) }}$ Data calculated from $w_{\text {cycles, }}, M_{\mathrm{n} \text { cycles }}$ and $M_{\mathrm{n}}$ SEC (see text) 

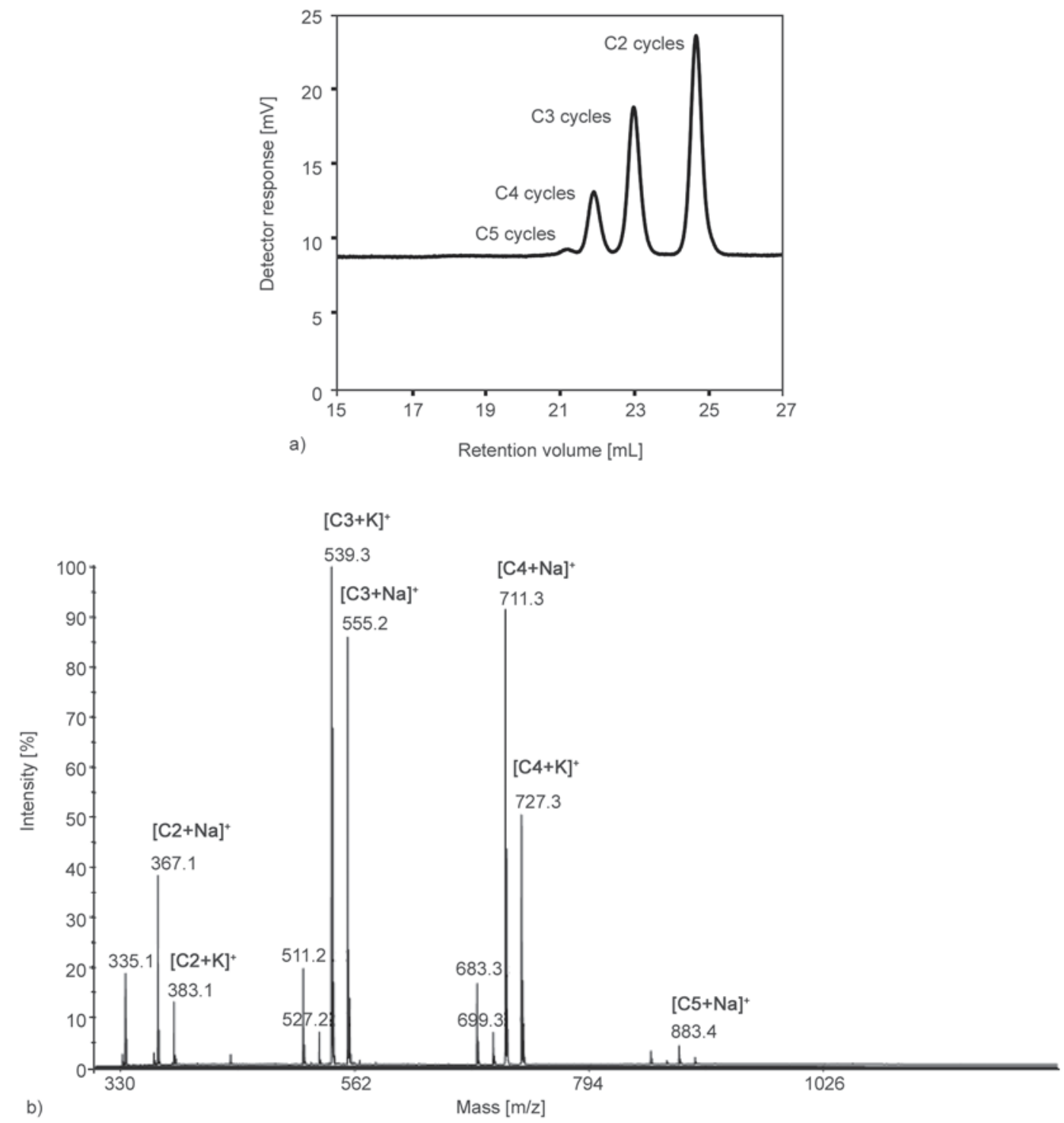

Figure 3. Analysis of the THF soluble fraction of PBS samples, (a) SEC in THF and (b) positive MALDI-TOF mass spectrum obtained in reflector mode (HABA matrix). Peaks at $\mathrm{m} / \mathrm{z} 511.2$ and 683.3 correspond to $\mathrm{CH}_{2}=\mathrm{CHCO}\left(\mathrm{C}_{8} \mathrm{H}_{12} \mathrm{O}_{4}\right)_{\mathrm{DP}} \mathrm{O}\left(\mathrm{CH}_{2}\right)_{4} \mathrm{OH}$ with $\mathrm{DP}=6$ and 8 , respectively.

by integrating the chromatograms excluding or not the molar mass range corresponding to oligomers $\left(100-1000 \mathrm{~g} \cdot \mathrm{mol}^{-1}\right)($ Table 2$)$.

\subsection{Comparison of molar mass data obtained by ${ }^{1} \mathrm{H}-\mathrm{NMR}$ and SEC}

The number-average molar mass of PBS2 to PBS7 obtained via chain-ends quantification by ${ }^{1} \mathrm{H}-\mathrm{NMR}$ was significantly lower than that measured by using SEC (both without correction for cyclic oligomers). This confirms the trend reported for polylactones and polylactides by several authors. Hiltunen et al. [20] measured molar masses 2-3 times smaller by titration than by SEC. Kowalsky et al. [21] and Save et al. [23] reported the same feature and found that the error depends on the chemical structure of the polymer and its mass range. They proposed a correction factor ranging from 0.54 to 0.58 depending on the polymer. For PBS, Lahcini et al. [19] found that measurements by SEC in chloroform calibrated with polystyrene standards caused an overestimation of the molar mass by $80-100 \%$ compared to universal calibration. Actually, the values determined by SEC can vary significantly depending on the detector and/or on the calibration for PBS samples. In the present study, the values determined by SEC overestimated the real $\overline{M_{\mathrm{n}}}$ by at least $50 \%$, partly due to SEC calibration using PMMA hydro- 
dynamic volumes which are different from those of the PBS and partly because of baseline errors due to oligomers.

Note that the molar mass determined by ${ }^{1} \mathrm{H}-\mathrm{NMR}$ or by SEC by taking cyclic oligomers into account was much different from that with no correction. Although the oligomers represent a small mass fraction of the polymer ( $w_{\text {cyclic }} \approx 0.9$ to $2.1 \mathrm{wt} \%$ ), the number of these cycles is high in comparison with the number of linear chains. As an example the number of moles of cycles in $1 \mathrm{~g}$ of PBS 5 is $n_{\text {cycles }}=$ $w_{\text {cycles }} / M_{\text {n cycles }} \sim 0.003$ mole and the number of moles of long chains is $n_{\text {chains }}=\left(100-w_{\text {chains }}\right) / M_{\mathrm{n} \text { chains }} \sim$ 0.002 mole ( $w_{\text {cycles }}$ is the mass percentage of cycles). Thus it is roughly estimated to be 1.5 cyclic molecule per PBS linear chain for PBS with $\overline{M_{\mathrm{n}}} \sim$ $48550 \mathrm{~g} \cdot \mathrm{mol}^{-1}$ (the data for other PBS is listed in Table 2). As a consequence, the corrected $\overline{M_{\mathrm{n}}}$ is much lower than the data derived without considering cyclic oligomers. Indeed, this is particularly true for samples with a high molar mass.

Finally, despite the experimental inaccuracies linked with the elution of low molar mass compounds, SEC technique and ${ }^{1} \mathrm{H}-\mathrm{NMR}$ provided consistent $\overline{M_{\mathrm{n}}}$ results when cyclic oligomers were integrated into the calculation.

\subsection{Correlation between intrinsic viscosity and molar mass.}

Figure 4 and Figure 5 show the plot of $\ln [\eta]$ versus $\ln \overline{M_{\mathrm{n}}}$ for PBS samples in 50/50 wt\% 1,2-dichlorobenzene/phenol and in chloroform respectively, where $\overline{M_{\mathrm{n}}}$ values were determined by the different methods presented previously (SEC and ${ }^{1} \mathrm{H}-\mathrm{NMR}$ ), and $[\eta]$ is the average of the Huggins and Kramer dual extrapolation values. The linear relationship between $\ln [\eta]$ and $\ln \bar{M}_{\mathrm{n}}$ was obtained by the least squares linear regression method. The values of equivalent $a$ and $k$ were obtained from the slope and intercept of the axis, respectively.

The values of equivalent $k$ and $a$ are presented in Table 3 as a function of the solvent used to determine the intrinsic viscosities and the method used to measure the molar mass.

Equivalent $a$ and $k$ values can be compared to those obtained by Imaizumi et al. [15] in chloroform at $40^{\circ} \mathrm{C},[\eta]=2.75 \cdot 10^{-4} \cdot{\overline{M_{\mathrm{n}}}}^{0.75}$. Molar masses were determined by SEC with polystyrene standards calibration. On the other hand Liu et al. [16] proposed $[\eta]=1.706 \cdot 10^{-4} \cdot \bar{M}_{\mathrm{n}}^{0.79}$. They determined the MHS

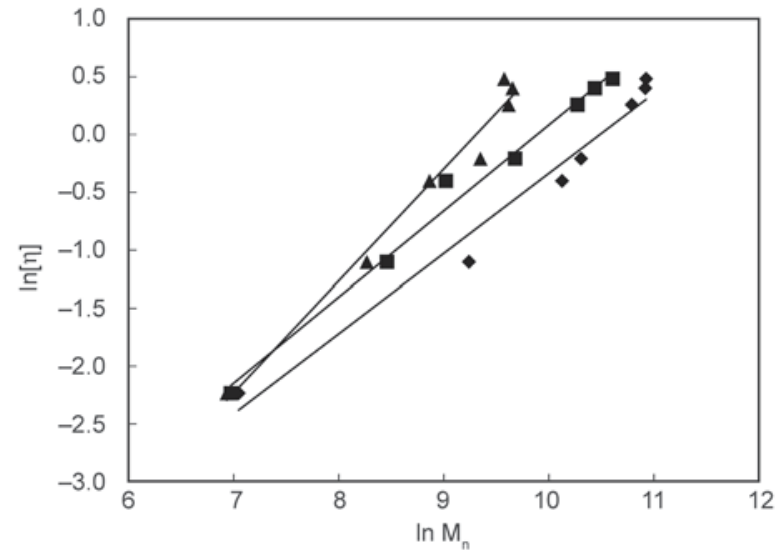

Figure 4. Relation between $\ln [\eta]$ and $\ln \overline{M_{\mathrm{n}}}$ for PBS samples in 50/50 wt $\%$ 1,2-dichlorobenzene/phenol at $25^{\circ} \mathrm{C}$ with $[\eta]$ in $\mathrm{dL} \cdot \mathrm{g}^{-1}$ and $\overline{M_{\mathrm{n}}}$ in $\mathrm{g} \cdot \mathrm{mol}^{-1} \cdot \overline{M_{\mathrm{n}}}$ determined ( $\bullet$ by SEC in HFIP, ( $\boldsymbol{\bullet})$ end-group analysis and $(\boldsymbol{\Delta})$ end-group analysis considering cyclic oligomers.

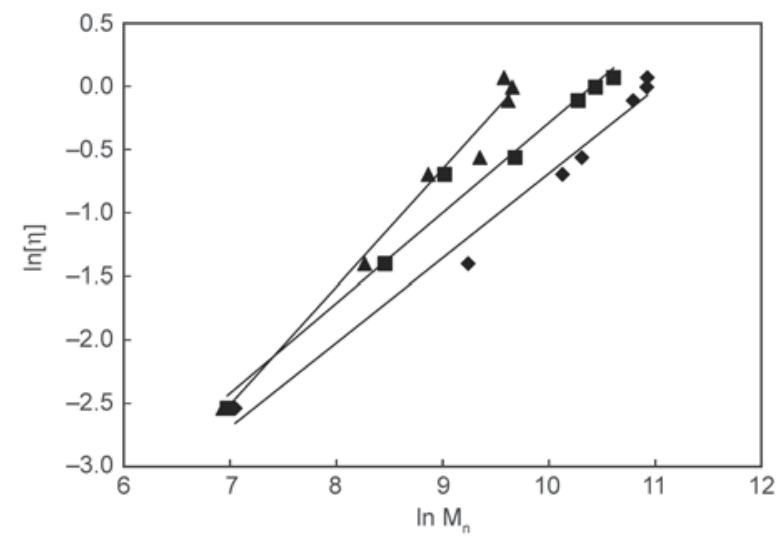

Figure 5. Relation between $\ln [\eta]$ and $\ln \overline{M_{\mathrm{n}}}$ for PBS samples in chloroform at $25^{\circ} \mathrm{C}$ with $[\eta]$ in $\mathrm{dL} \cdot \mathrm{g}^{-1}$ and $\overline{M_{\mathrm{n}}}$ in $\mathrm{g} \cdot \mathrm{mol}^{-1} \cdot \overline{M_{\mathrm{n}}}$ determined ( $)$ by SEC in HFIP, $(\boldsymbol{\square})$ end-group analysis and ( $\boldsymbol{\Delta})$ end-group analysis considering cyclic oligomers.

parameters in 50/50 $\mathrm{wt} \%$ phenol/tetrachloroethane with $\overline{M_{\mathrm{n}}}$ values obtained by SEC measurements in chloroform with polystyrene calibration $\left(\overline{M_{\mathrm{n}}}<\right.$ $\left.100000 \mathrm{~g} \cdot \mathrm{mol}^{-1}\right)$. Recently Garin et al. [17] proposed $[\eta]=39.94 \cdot 10^{-5} \cdot{\overline{M_{\mathrm{n}}}}^{0.71}$ in chloroform at $30^{\circ} \mathrm{C}$ with molar mass determined by SEC with a triple detection system. $[\eta]$ is expressed in $\mathrm{dL} \cdot \mathrm{g}^{-1}$.

\subsection{Correlation between reduced viscosity and molar mass}

The Mark-Houwink-Sakurada parameters are largely used in order to calculate molar masses from intrinsic viscosity measurements but the methodology requires the analysis of several concentrations of one polymer. In routine characterization only the reduced viscosity, $\eta_{\text {red }}$, of polyesters is measured 
Table 3. Equivalent $k$ and $a$ parameters in chloroform and 50/50 wt $\%$ 1,2-dichlorobenzene/phenol to calculate the molar mass for different method of determination. $[\eta]$ in $\mathrm{dL} \cdot \mathrm{g}^{-1}$.

\begin{tabular}{|c|c|c|c|}
\hline $\begin{array}{c}\text { Solvent used for } \\
\text { determining viscosity }\end{array}$ & Method for molar mass determination & $\begin{array}{c}\text { Range of } \bar{M}_{n} \\
{[\mathrm{~g} / \mathrm{mol}]}\end{array}$ & $\begin{array}{c}\text { Equivalent } \\
\text { Mark-Houwink-Sakurada relation }^{\text {a) }} \\
\end{array}$ \\
\hline \multirow{3}{*}{$\begin{array}{c}50 / 50 \mathrm{wt} \% \\
\text { 1,2-dichlorobenzene/phenol }\end{array}$} & SEC in HFIP $\left.{ }^{b}\right)$ & $1150-55550$ & {$[\eta]=7.1 \cdot 10^{-4} \cdot \bar{M}_{\mathrm{n}}^{0.69}$} \\
\hline & $\begin{array}{l}\text { End-group analysis without considering } \\
\text { cyclic oligomers }\end{array}$ & $1070-40400$ & {$[\eta]=6.4 \cdot 10^{-4} \cdot \bar{M}_{\mathrm{n}}^{0.74}$} \\
\hline & $\begin{array}{l}\text { End-group analysis considering cyclic } \\
\text { oligomers }\end{array}$ & $1030-15600$ & {$[\eta]=1.2 \cdot 10^{-4} \cdot \bar{M}_{\mathrm{n}}^{0.97}$} \\
\hline \multirow{3}{*}{ Chloroform } & SEC in HFIP ${ }^{b}$ & $1150-55550$ & {$[\eta]=6.4 \cdot 10^{-4} \cdot \bar{M}_{\mathrm{n}}^{0.67}$} \\
\hline & $\begin{array}{l}\text { End-group analysis without considering } \\
\text { cyclic oligomers }\end{array}$ & $1070-40400$ & {$[\eta]=6.1 \cdot 10^{-4} \cdot \bar{M}_{\mathrm{n}}^{0.71}$} \\
\hline & $\begin{array}{l}\text { End-group analysis considering cyclic } \\
\text { oligomers }\end{array}$ & $1030-15600$ & {$[\eta]=1.2 \cdot 10^{-4} \cdot \bar{M}_{\mathrm{n}}^{0.93}$} \\
\hline
\end{tabular}

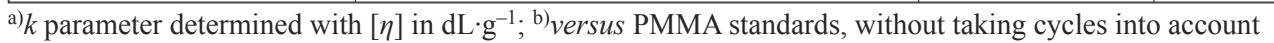

because obtaining this data is much less time consuming. Only one polyester solution is prepared and analyzed. In the polyester industry, it is common practice to calculate $\overline{M_{\mathrm{n}}}$ with the help of simple linear empirical relationships between molar mass and reduced viscosity. As an example, very helpful equations have been proposed by Gantillon et al. [36] for poly(ethylene terephthalate).

In the same way, it is possible to apply this approach to PBS and plot $\bar{M}_{\mathrm{n}}$ values versus $\eta_{\text {red. }}$. The example

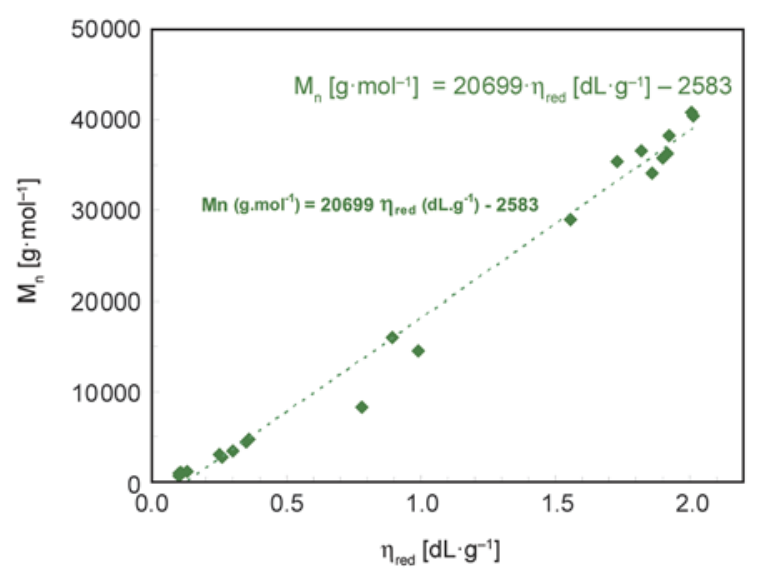

Figure 6. Number average molar mass versus reduced viscosity $\eta_{\text {red }}$ measured for a $5 \mathrm{~g} \cdot \mathrm{L}^{-1}$ PBS solution in $50 / 50 \mathrm{wt} \%$ dichlorobenzene/phenol at $25^{\circ} \mathrm{C}$. Molar mass determined by ${ }^{1} \mathrm{H}-\mathrm{NMR}$ without correction for the cyclic oligomers. depicted in Figure 6 is the most reliable one, for which we have the more data; the different relationships for obtaining $\overline{M_{\mathrm{n}}}$ data are summarized in Table 4

\section{Conclusions}

The determination of the molar mass of polyesters is a difficult task. Here a series of PBS samples was synthesized with molar masses ranging from 1000 to $40000 \mathrm{~g} \cdot \mathrm{mol}^{-1}$. They contained a fraction of cyclic oligomers produced during the esterification step of the synthesis process. This fraction was deliberately not removed by purification in order to evaluate its effect. The characterization of the solution viscosity of these polymers was performed in chloroform, a typical solvent for PBS and in a mixture of dichlorobenzene/phenol, a classical solvent for semiaromatic polyesters. The molar mass of the polymers was determined using different techniques. The first one was an easily available method but did not provide an absolute value of $\overline{M_{\mathrm{n}}}$. More reliable data were obtained using ${ }^{1} \mathrm{H}-\mathrm{NMR}$ spectroscopy. In addition a correction was proposed to account for the presence of PBS cyclic oligomers with a number average degree of polymerization, $\mathrm{DPn}=4,6,8$ and 10. The proposed sets of Mark-Houwink-Sakurada parameters and empirical relationships were

Table 4. Empirical relationship for determining $\overline{M_{\mathrm{n}}}$ from reduced viscosity measurements. $\eta_{\mathrm{red}}$ in $\mathrm{dL} \cdot \mathrm{g}^{-1}$. Concentration of the solution for the viscosity measurement $=5 \mathrm{~g} \cdot \mathrm{L}^{-1}$.

\begin{tabular}{|c|c|l|l|}
\hline $\begin{array}{c}\text { Solvent used for } \\
\text { determining } \eta_{\text {red }}\end{array}$ & $\begin{array}{c}\text { Range of } \mathbf{M}_{\mathbf{n}} \\
{\left[\mathbf{g} \cdot \mathbf{m o l}^{-1} \mathbf{l}\right.}\end{array}$ & \multicolumn{1}{|c|}{$\overline{\mathbf{M}}_{\mathbf{n}}=\mathbf{f}\left(\boldsymbol{\eta}_{\text {red }}\right)$} & \multicolumn{1}{|c|}{$\overline{\mathbf{M}}_{\mathbf{n}}$ value corresponds to that measured by: } \\
\hline \multirow{2}{*}{$\begin{array}{c}50 / 50 \mathrm{wt} \% \\
\text { 1,2-dichlorobenzene/phenol }\end{array}$} & $1150-55500$ & $\bar{M}_{\mathrm{n}}=29000 \cdot \eta_{\mathrm{red}}+700$ & SEC in HFIP ${ }^{\mathrm{a})}$ \\
\cline { 2 - 4 } & $1070-40400$ & $\bar{M}_{\mathrm{n}}=20600 \cdot \eta_{\mathrm{red}}-2580$ & End-group analysis without considering cyclic oligomers \\
\cline { 2 - 4 } & $1030-15600$ & $\bar{M}_{\mathrm{n}}=7500 \cdot \eta_{\mathrm{red}}+1700$ & End-group analysis considering cyclic oligomers \\
\hline \multirow{3}{*}{ Chloroform } & $1150-55550$ & $\bar{M}_{\mathrm{n}}=47000 \cdot \eta_{\mathrm{red}}-1300$ & SEC in HFIP ${ }^{\mathrm{a})}$ \\
\cline { 2 - 4 } & $1070-40400$ & $\bar{M}_{\mathrm{n}}=33000 \cdot \eta_{\mathrm{red}}-4500$ & End-group analysis without considering cyclic oligomers \\
\cline { 2 - 4 } & $1030-15600$ & $\bar{M}_{\mathrm{n}}=12000 \cdot \eta_{\mathrm{red}}+1100$ & End-group analysis considering cyclic oligomers \\
\hline
\end{tabular}

a)versus PMMA standards, without taking cycles into account 
very helpful to calculate $\overline{M_{\mathrm{n}}}$ either from the determination of the intrinsic viscosity or with a simple measurement of the reduced viscosity, $\eta_{\text {red. }}$.

\section{Acknowledgements}

This project was supported by the French Région RhôneAlpes and FEFER in the framework of the Thalia project. It has also been supported by Roquettes Frères and by Texinov. We thank the NMR Polymer Center of the Institut de Chimie de Lyon (FR5223) for assistance and access to the NMR facilities.

\section{References}

[1] Lourenço A. V.: Recherches sur les composés polyatomiques. Annales de Chimie et de Physique, 67, 257339 (1863).

[2] Flory P. J.: Early accounters with condensation polymers. in 'Principles of polymer chemistry' (ed.: Flory P. J.) Cornell University Press, Ithaca, 12-19 (1953).

[3] Carothers W. H., Arvin G. A.: Studies on polymerization and ring formation. II. Poly-esters. Journal of the American Chemical Society, 51, 2560-2570 (1929). DOI: $10.1021 / \mathrm{ja} 01383 \mathrm{a} 042$

[4] Xu J., Guo B. H.: Microbial succinic acid, its polymer poly(butylene succinate), and applications. in 'Plastics from bacteria' (Ed.: Chen G. G. Q.) Springer, Berlin, 347-388 (2010).

[5] Ichikawa Y., Mizukoshi T.: Bionolle (polybutylenesuccinate). in 'Synthetic biodegradable polymers' (ed.: Rieger B., Künkel A., Coates G. W., Reichardt R., Dinjus E., Zevaco T. A.) Springer, Berlin, 285-313 (2012). DOI: $10.1007 / 122011 \quad 145$

[6] Papageorgiou G. Z., Achilias D. S., Bikiaris D. N.: Crystallization kinetics of biodegradable poly(butylene succinate) under isothermal and non-isothermal conditions. Macromolecular Chemistry and Physics, 208, 1250-1264 (2007).

DOI: $10.1002 / \mathrm{macp} .200700084$

[7] Chung H. S., Lee J. W., Kim D. H., Jun J. N., Lee S. W.: Polyester resin and a process for preparing the same. U.S. Patent 6063895A, USA(2000).

[8] Imaizumi M., Kimura H., Fujihira R., Ichikawa Y., Suzuki J., Moteki Y., Fujimaki T., Takiyama E.: Aliphatic polyester resin and method for producing same. U.S. Patent 5714569 A, USA (1998).

[9] Aoshima T., Miki Y., Kumazawa K., Katou S., Uyeda T., Hoshino T., Shintani N., Yamagishi K., Isotani A.: Polyester derived from biomass resources and method for production thereof. U.S. Patent 20090171037 A1, USA (2009).

[10] Han Y-K., Um J. W., Im S. S., Kim B. C.: Synthesis and characterization of high molecular weight branched PBA. Journal of polymer science Part A: Polymer Chemistry, 39, 2143-2150 (2001).

DOI: $10.1002 /$ pola.1190.abs
[11] Singley E. J., Daniel A., Person D., Beckman E. J.: Determination of Mark-Houwink parameters for poly(N-vinylformamide). Journal of Polymer Science Part A: Polymer Chemistry, 35, 2533-2534 (1997).

DOI: 10.1002/(SICI)1099-0518(19970915)35:12<2533 $\because$ AID-POLA24>3.0.CO;2-7

[12] Yin N., Zeng Z-X., Xue W-L.: Intrinsic viscositynumber average molecular weight relationship for poly(1,4-butylene adipate) diol. Journal of Applied Polymer Science, 117, 1883-1887 (2010). DOI: 10.1002/app.32058

[13] Zeng Z., Sun L., Xue W., Yin N., Zhu W.: Relationship of intrinsic viscosity to molecular weight for poly (1, 4-butylene adipate). Polymer Testing, 29, 66-71 (2010). DOI: $10.1016 /$ j.polymertesting.2009.09.006

[14] Kasaai M. R., Arul J., Charlet G.: Intrinsic viscositymolecular weight relationship for chitosan. Journal of Polymer Science Part B: Polymer Physics, 38, 25912598 (2000).

DOI: 10.1002/1099-0488(20001001)38:19<2591::AIDPOLB110>3.0.CO;2-6

[15] Imaizumi X., Okiro Y., Yoshikawa K., Koyama K.: Relationship between viscosity and molecular weight $\left(M_{\mathrm{W}}\right)$ of PBS and PBSA determined by SEC-LALLS and SEC-viscometry (in Japanese). Seikei-Kakou, 15, 419-423 (2003).

[16] Liu X-H., Huang G-B., Wang S-P.: Synthesis of high molecule weight poly(butylene succinate) and relationship of molecule weight with intrinsic viscosity. China Plastics Industry, 36, 14-16 (2008).

[17] Garin M., Tighzert L., Vroman I., Marinkovic S., Estrine B.: The influence of molar mass on rheological and dilute solution properties of poly(butylene succinate). Journal of Applied Polymer Science, 131, 40887/1-40887/7 (2014).

DOI: 10.1002/APP.40887

[18] Yashiro T., Kricheldorf H. R., Huijser S.: Syntheses of polyesters from succinic anhydride and various diols catalyzed by metal triflates. Macromolecular Chemistry and Physics, 210, 1607-1616 (2009).

DOI: $10.1002 / \mathrm{macp} .200900189$

[19] Lahcini M., Qayouh H., Yashiro T., Simon P., Kricheldorf H. R.: Syntheses of poly(butylene succinate) by means of non-toxic catalysts. Journal of Macromolecular Science Part A: Pure and Applied Chemistry, 47, 503-509 (2010). DOI: $10.1080 / 10601321003741875$

[20] Hiltunen K., Härkönen M., Seppälä J. V., Väänänen T.: Synthesis and characterization of lactic acid based telechelic prepolymers. Macromolecules, 29, 86778682 (1996). DOI: $10.1021 / \mathrm{ma} 960402 \mathrm{k}$

[21] Kowalski A., Duda A., Penczek S.: Polymerization of L,L-lactide initiated by aluminum isopropoxide trimer or tetramer. Macromolecules, 31, 2114-2122 (1998). DOI: $10.1021 / \mathrm{ma} 971737 \mathrm{k}$ 
[22] Kricheldorf H. R., Eggerstedt S.: Macrocycles 2. Living macrocyclic polymerization of $\varepsilon$-caprolactone with 2,2-dibutyl-2-stanna-1,3-dioxepane as initiator. Macromolecular Chemistry and Physics, 199, 283-290 (1998). DOI: $10.1002 /($ SICI) 1521-3935(19980201)199:2<283 $\because: A I D-M A C P 283>3.3 . C O ; 2-0$

[23] Save M., Schappacher M., Soum A.: Controlled ringopening polymerization of lactones and lactides initiated by lanthanum isopropoxide, 1. General aspects and kinetics. Macromolecular Chemistry and Physics, 203, 889-899 (2002).

DOI: 10.1002/1521-3935(20020401)203:5/6<889:: AID-MACP889>3.0.CO;2-O

[24] Pasch H., Rode K.: Use of matrix-assisted laser desorption/ionization mass spectrometry for molar masssensitive detection in liquid chromatography of polymers. Journal of Chromatography A, 699, 21-29 (1995).

DOI: 10.1016/0021-9673(95)00061-Q

[25] Montaudo M. S.: MALDI for the estimation of viscosity parameters. A modified method which applies also to polycondensates. Polymer, 45, 6291-6298 (2004). DOI: $10.1016 /$ j.polymer.2004.07.011

[26] Jacquel N., Freyermouth F., Fenouillot F., Rousseau A., Pascault J. P., Fuertes P., Saint-Loup R.: Synthesis and properties of poly(butylene succinate): Efficiency of different transesterification catalysts. Journal of Polymer Science Part A: Polymer Chemistry, 49, 5301-5312 (2011).

DOI: $10.1002 /$ pola.25009

[27] Yuan Y., Johnson F., Cabasso I.: Polybenzimidazole (PBI) molecular weight and Mark-Houwink equation. Journal of Applied Polymer Science, 112, 3436-3441 (2009).

DOI: 10.1002/app.29817

[28] Solomon O. F., Ciută I. Z. : Détermination de la viscosité intrinsèque de solutions de polymères par une simple détermination de la viscosité. Journal of Applied Polymer Science, 24, 683-686 (1962).

DOI: 10.1002/app.1962.070062414
[29] Kuwahara N. J.: On the polymer-solvent interaction in polymer solutions. Journal of Polymer Science Part A: General Papers, 1, 2395-2406 (1963).

DOI: $10.1002 /$ pol.1963.100010717

[30] Rao M. V. R. M., Yaseen M.: Determination of intrinsic viscosity by single specific viscosity measurement. Journal of Applied Polymer Science, 31, 2501-2508 (1986). DOI: 10.1002/app.1986.070310811

[31] Chee K. K.: A critical evaluation of the single-point determination of intrinsic viscosity. Journal of Applied Polymer Science, 34, 891-899 (1987).

DOI: 10.1002/app.1987.070340301

[32] Chuah H. H., Lin-Vien D., Soni U.: Poly(trimethylene terephthalate) molecular weight and Mark-Houwink equation. Polymer, 42, 7137-7139 (2001). DOI: 10.1016/S0032-3861(01)00043-X

[33] Zhao J. B., Li K. Y., Yang W. T.: Chain extension of polybutylene adipate and polybutylene succinate with adipoyl- and terephthaloyl-biscaprolactamate. Journal of Applied Polymer Science, 106, 590-598 (2007). DOI: 10.1002/app.26635

[34] Chrissafis K., Paraskevopoulos K. M., Bikiaris D. N.: Thermal degradation mechanism of poly(ethylene succinate) and poly(butylene succinate): Comparative study. Thermochimica Acta, 435, 142-150 (2005). DOI: $10.1016 /$ j.tca.2005.05.011

[35] Bikiaris D. N., Achilias D. S.: Synthesis of poly(alkylene succinate) biodegradable polyesters, Part II: Mathematical modelling of the polycondensation reaction. Polymer, 49, 3677-3685 (2008).

DOI: $10.1016 /$ j.polymer.2008.06.026

[36] Gantillon B., Spitz R., McKenna T. F.: The solid state postcondensation of PET, 2. Toward the development of a new dispersed phase solid state process. Macromolecular Materials and Engineering, 289, 106-112 (2004). DOI: $10.1002 /$ mame. 200300290 